\title{
PUTTING A STICKING PLASTER ON A GAPING WOUND - EXPLORING THE PROVISION BEING MADE IN ENGLISH SECONDARY SCHOOLS TO SUPPORT MENTAL HEALTH AND MENTAL WELL-BEING
}

\author{
Dr Max Coates ${ }^{*}$ and Dr Domini Bingham ${ }^{* *}$
}

\begin{abstract}
This is a small-scale study utilising both questionnaires and semi-structured interviews.

Against the backdrop of widespread interest in the area of mental health/wellbeing by the UK government and also by the media, the study starts to explore the provision being made by secondary schools.

The study suggests that the actions being taken nationally lack coherence. Even within the schools themselves, there is evidence of a fragmented approach as mental health/well-being initiatives are added to existing provision being offered by pastoral staff and formally appointed councillors.

As new waves of pressure from social media, gender identity, examination stress and personal identity are held to impact mental health/well-being issues schools understand themselves as being the first responder. In turn, the majority of those interviewed in the study have a perception that support services such as Child and Adult Mental Health Services (CAMHS) and educational psychologists are less accessible as a result of budgetary constraints.
\end{abstract}

\section{INTRODUCTION}

In 1978, Baroness Warnock's report ${ }^{1}$ on special education was published. It suggested that around $20 \%$ of the school population could be identified as having some level of special needs. In its wake, in 1982, schools were beginning to create

\footnotetext{
* Revd. Professor Max Coates DFCOT, MA, BA(Hons), BEd(Hons), SFHEA, Dip.Ed(Adv), FCOT, BCTS, ACP, Cert.Ed.

${ }^{* *}$ Dr. Domini Bingham BA (Hons), PG.Dip CIM., PGCE(PCET)., MA., EdD.

1 Warnock, H. (1978) Special Educational Needs. Report of the Committee of Enquiry into the Education of Handicapped Children and Young People. London, HMSO.
} 
registers of pupils who were deemed to have such needs. For many schools the register was a catchall recording everything from dyslexia to asthma. In Gaywood Park High School in King's Lynn, where one of the authors was working at the time, that $20 \%$ figure was achieved. Certainly, the school had significant numbers of pupils who presented emotional and behavioural difficulties. However, very few, probably less than $0.3 \%$, were identified as having mental health/well-being issues. In year 10 there was just a single student who made the cut. This was a girl who had become deeply immersed in $\mathrm{Oz}$ and Henson's film The Dark Crystal (1982), ${ }^{2}$ to the point where she became psychotic and required treatment as an inpatient in a psychiatric hospital.

Though the focus of this study and research is centred on England it would be inappropriate to see mental health/well-being as a geographically contained. The World Health Organisation (WHO, 2018) ${ }^{3}$ has stated that:

Worldwide 10 to $20 \%$ of children and adolescents experience mental disorders. Half of all mental illnesses begin by the age of 14, three quarters by their mid-20s. Neuropsychiatric conditions are the leading cause of disability in young people in all regions. If untreated these conditions severely influence children's development, their educational attainments and their potential to live fulfilling and productive lives. Children with mental disorders face major challenges with stigma, isolation and discrimination, as well as a lack of access to health care and education facilities, in violation of their fundamental human rights.

$(2018: 1)$

The contemporary situation is very different, with mental health/well-being achieving prominence across the media in the UK and in many other countries. The context in which schools are working has also changed significantly, for example; cyber-bullying, anxiety over body image, substance abuse, heightened pressure around examination performance, gender identity and arguably the loss of a unified societal narrative have all come to the fore.

Concurrently, the diagnosis of mental health issues has become more sophisticated and nuanced. The controversial American based Diagnostic and

\footnotetext{
2 Oz, F. and Henson, J. (1982) The Dark Crystal. Hollywood, Universal Studios. American Psychiatric Association (2013) Diagnostic and Statistical Manual of Mental Disorders, 5th Edition (DSM-5.) Washington DC. American Psychiatric Association.

3 World Health Organisation (2018) Mental Health a state of wellbeing. Geneva, WHO. https://www.who.int/features/factfiles/mental_health/en (Accessed 17 ${ }^{\text {th }}$ July 2019)
} 
Statistical Manual (DSM-5) (2013) now lists more than 250 disorders. In its last format, they actually sought entries from the general public.

Recently, the Guardian (2018) ${ }^{4}$ noted:

Almost four in five (78\%) teachers have seen a pupil struggle with a mental health problem in the past year, with one in seven (14\%) cases involving suicidal thoughts or behaviour.

Anxiety is the most common problem, with two-thirds of the 300 teachers surveyed by the mental health charity stem 4 coming across a young person at their school with the condition in the past year. Significant minorities of teachers have also encountered at least one pupil with depression (45\%), an eating disorder such as anorexia (30\%), self-harming (28\%) or addiction $(10 \%)$.

Whether through occurrence or perception, mental health/well-being has moved up the agenda in schools. It is, however, extremely difficult to plot the incidence of such issues over time as definitions change. In the quotation from the Guardian (2018) the main diagnostic agency appears to be teachers. Whilst they may be accomplished pedagogues, they are less likely to be psychiatric clinicians. Further mental health/well-being is described as a self-evident entity rather than a complex composite. It is suggested that we may have moved from analysis to anecdote in terms of the approach being taken to this challenging subject.

This research does not seek to define the parameters of mental health/wellbeing, but rather it has sought to engage with the perceptions which are held in schools. It has begun to explore the provision actually being made in English secondary schools to offer support in this area.

\section{LITERATURE REVIEW}

An engagement with the literature around adolescent mental health is akin to opening Pandora's Box. The following are offered as an incomplete index of the different categories of literature: psychology, policy documents, self-help literature, prevalence studies.

What soon becomes apparent is the lack of unity in the literature. Mental health/well-being is discussed as if there is some level of consensus about its

${ }^{4}$ Campbell, D. (2018) Children face mental health epidemic say teachers. Manchester, The Guardian. 


\section{PUTTING A STICKING PLASTER ON A GAPING WOUND}

substance. Bond et al. (2007) ${ }^{5}$ conducted research into social and school connectedness amongst secondary school pupils as predictors of issues such as substance abuse and mental health. However, their definitions around mental health soon take refuge in indices of anxiety and depression rather than in an overarching evaluation.

Fabiano and Evans (2019) ${ }^{6}$ assert that there is a need to address a substantial and imminent issue:

It is unlikely that there was ever a time in history when school mental health practitioners' provision of effective intervention was more important. The current school context includes acts of serious violence and the public's concern that untreated mental health impairment contributes to these acts.

They go on to provide a useful tour of good practice in the area of mental health and well-being. However, their framework starts with a consideration of a range of presenting problems with commissioned authors offering strategies for resolution or containment. For example, Fabiano and Pyle (2018), ${ }^{7}$ writing in the Journal of School Mental Health, review best practices for responding to Attention Deficit/ Hyperactivity Disorder (ADHD). This is offered as an accepted disorder. There follows a review of strategies including school response and parenting. It is perhaps pertinent to ask a deeper question: 'What is it that we are considering?' There is a fascinating study by Madsen, Ersboll, Olsen, Palmer and Obel $(2015)^{8}$ that found ADHD varied within a geographical location despite the same overarching health care availability. In Great Britain, Sellers, Maughan, Pickles, Thapar, Collishaw (2015), ${ }^{9}$ in a longitudinal study, found that there was a reduction in the perception

\footnotetext{
5 Bond, L., Butler, H., Thomas, L., Carlin, J. Glover, S., Bowes, G., and Patton, G. (2007) Social and School Connectedness in Early Secondary School as Predictors of Late Teenage Substance Use, Mental Health, and Academic Outcomes. Melbourne, University of Melbourne.

${ }^{6}$ Fabio, G. \& Evans, S. (2019) Introduction to the Special Issue of School Mental Health on Best Practices in Effective Multi-tiered Intervention Frameworks School Mental Health (2019) 11:1-3.

7 Fabiano, G. A., \& Pyle, K. (2019). Best practices in school mental health for attention deficit/hyperactivity disorder. School Mental Health (2019) 11:72-91).

8 Madsen KB, Ersboll AK, Olsen J, Parner E, Obel C. 2015. Geographic analysis of the variation in the incidence of ADHD in a country with free access to healthcare: a Danish cohort study. Int. J. Health Geogr. 14:24

9 Sellers R, Maughan B, Pickles A, Thapar A, Collishaw S. Trends in parent- and
} 


\section{THE BUCKINGHAM JOURNAL OF EDUCATION}

of behavioural problems in pre-adolescent children and that this may be due to contextual factors rather than an increase in behavioural problems. So, are the common medications prescribed for ADHD such as is Ritalin or Adderall the appropriate panaceas?

Fabio and Evans (2019) ${ }^{10}$ provide a useful summary of a model based on a hierarchy of ascending support, multi-tiered system of support (MTSS). This model is derived from literacy support. Its strength lies with a systematised support model which monitors a given individual's problem and responds with increasing levels of intensity. The intention is to keep the mental health issue in 'outpatients' rather than 'intensive care'.

Nevertheless, there appears to be little that provides an accessible model for understanding mental health/well-being. Perhaps the most pragmatic descriptor is that offered by the World Health Organisation (WHO, 2014): ${ }^{11}$

Mental health is defined as a state of well-being in which every individual realizes his or her own potential, can cope with the normal stresses of life, can work productively and fruitfully, and is able to make a contribution to her or his community.

This definition offers a degree of resonance with the authors and indeed it is widely used. It is, however, difficult to find its source or basis. In the same document they make the following points, again these are offered by the WHO as being self-evidently true:

- Mental health is more than the absence of mental disorders. Mental health is an integral part of health; indeed, there is no health without mental health.

- Mental health is determined by a range of socioeconomic, biological and environmental factors.

- Cost-effective public health and intersectoral strategies and interventions exist to promote, protect and restore mental health.

teacher-rated emotional, conduct and ADHD problems and their impact in prepubertal children in Great Britain: 1999-2008. J Child Psychol Psychiatry. 2015; 56(1):49-57.

${ }^{10}$ Fabio, G. \& Evans, S. (2019) Introduction to the Special Issue of School Mental Health on Best Practices in Effective Multi-tiered Intervention Frameworks. School Mental Health (2019) 11:1-3.

11 World Health Organisation (2018) Child and adolescent mental health https://www. who.int/mental_health/maternal-child/child_adolescent/en Geneva, WHO (Accessed $20^{\text {th }}$ July 2019). 


\section{PSYCHOLOGY}

This offers a problematic journey into the understanding and response to mental illness/well-being. Some of the literature is technical, which does not lend itself to accessibility by lay people. Such complexity is appropriate in the discussion and response to pathology by health-care professionals, though it does not readily distil into 'handy hints' for resolving the challenges presented by mental health issues.

A further difficulty emerges as the writing on psychology splits down into a spectrum of views. Koenig (2019) ${ }^{12}$ suggests that there are six major schools of psychology: Behaviourism, Cognitivism, Functionalism, Humanistic/Gestalt, Psychodynamic and Systems Psychology. In general, these are less of a collective toolkit and more of a series of individualised position statements.

To some extent literature around psychology comes to a fork in the road. One fork engages with malfunction. This is not altogether surprising when you consider that so much of the study of the brain has been derived from the study of impairment. For example, there is the unfortunate case of Phineas Gage who in a railway accident in 1848 had a tamping rod pass through his head and in its wake allegedly suffered a personality change. The other fork followed by psychologists such as Seligman (1988), ${ }^{13}$ Csikszentmihalyi (1990), ${ }^{14}$ Perls (1994) ${ }^{15}$ and Erikson (Hayley 1999) ${ }^{16}$ sought to optimise the effective function of the sentient and cognitive activity of the brain.

Perhaps the route for mental health and well-being for the majority may well lie with the writings and research of these psychologists. Csikszentmihalyi (1990) published his research on the optimal state in his book flow, and arguably this is where most of us want to be, a place of calm consciousness.

${ }^{12}$ Koenig, D. (2019) "Six Major Schools of Thought in Psychology" Classroom Synonym. Com. https://classroom.synonym.com/six-major-schools-thought-psychology-2579. (Accessed $18^{\text {th }}$ August 2019).

${ }^{13}$ Seligman, M. (1988) 'People born after 1945 were ten times more likely to suffer from depression than people born 50 years earlier' in Buie, J. (ed.) 'Me' decades generate depression: individualism erodes commitment to others. Washington, DC: APA Monitor.

${ }^{14}$ Csikszentmihalyi, M. (1990). Flow: the psychology of optimal experience. New York, NY: Harper \& Row.

15 Perls, F. (1994) Gestalt Therapy: Excitement and Growth in the Human Personality Goldsboro. Gestalt Journal Press Inc.

${ }^{16}$ Hayley, J. (1999) Conversations with Milton H. Erickson, M.D., New York, WW Norton and Company. 
Coates $(2017)^{17}$ argued that:

It is unlikely that our brains have undergone any significant changes for perhaps 50,000 years. This means that our Palaeolithic ancestors, who were hunter-gatherers, were significantly like us. The same neural processing that enabled them to hunt woolly mammoths with relatively basic weapons enables us to run complex organisations such as factories, hospitals and academies.

There seem to be few limits on our creativity but significant limits on our capacity. Coates goes on to argue that much of the root of mental dysfunctionality lies with stress. Its contemporary usage is generally traced back to Hans Selye (1956). ${ }^{18}$ His primary work, for which he was nominated for a Nobel Prize in 1949, was in endocrinology. In essence, Selye researched the changes in the endocrine system when an organism was exposed to a stimulus or stressor. Tyrell $(2015)^{19}$ argues sustained stress (chronic) rather than the acute emergency operation of the endocrine system with its production of adrenaline and cortisol is detrimental to health. It can serve as a significant precursor to serious health issues problems around mental health/ well-being.

The argument being advanced is that the induction of a sustained stress-driven physiological state is likely to have a significant impact upon the thinking and well-being of an individual. The firing of the chain from the hypothalamus to the pituitary to the adrenal glands followed by flooding the body with adrenaline and cortisol will narrow thinking, reduce creative possibilities, tend to generate a defensive/aggressive response towards others and can erode memory. It will certainly generate anxiety and significant behavioural change.

\section{POLICY DOCUMENTS}

The setting of this research is limited to England. It is suggested that there are three key documents here: a Green Paper from the Department of Health and Social Care and the Department of Education (2017); ${ }^{20}$ the subsequent response

17 Coates, M. (2018) It's Doing My Head In. Ipswich, John Catt Educational.

18 Selye, H. (1956) The Stress of Life. New York, NY: McGraw-Hill.

19 Tyrrell, M. (2015) Uncommon psychotherapy. Oban: Uncommon Knowledge.

20 Department of Health and Social Care and The Department of Education (2017) Transforming Children and Young People's Mental Health Provision: a Green Paper. London, Crown. 
from the Department of Health and Social Care and the Department of Education (2018) $;{ }^{21}$ and Brown, R. (2018) ${ }^{22}$ Mental Health and Wellbeing Provision in Schools.

The Green Paper (2017) and the Government Response (2018) both recognise that there is a problem around mental health/well-being in schools and also make a commitment to provides resources to mitigate its impact. The paper follows a public consultation around these issues. There is a particular emphasis placed on the impact of social media, the provision of trained personnel in schools and the availability of improved access to mental health services. No mention is made of the stress induced by our high-stakes testing regime, substance abuse or dysfunctional parenting. The main recommendations of the Green Paper are structural and offer few insights on potential practice and how this might support efficacy in responding to the needs of both individuals and the school population as a whole.

As we roll-out the proposals through the trailblazers, we will have the opportunity to test how they link to other initiatives, such as the Department for Education's social mobility-focused 'opportunity areas'. This is a complex task, building on an already complex landscape, and while we are working to ambitious deadlines, implementation of the Green Paper proposals will take time to do properly.

(DHSC \& DfE 2018:18)

Brown (2018) offers a review of how schools' published policies support their mental health provision, and it includes information on statutory duties and pupil well-being. The explicit focus on statutory provision does constrain the report, for example; values are explored in terms of 'equality' and respect through 'antibullying policies'.

It is suggested that the review is significantly flawed in terms of conflating correlation and causality. Consider the following quotation:

Universal support in secondary schools included school well-being centres; school nurture approaches, school pastoral teams and home liaison workers; embedding mental health education within the curriculum, particularly in PSHE

${ }^{21}$ Department of Health and Social Care and The Department of Education (2018) Government Response to the Consultation on Transforming Children and Young People's Mental Health Provision: a Green Paper. London, Crown.

22 Brown, R. (2018) Mental Health and Wellbeing Provision in Schools. Review of published policies and information. Research Report. London Department for Education. 
and SEAL programmes; promoting exercise, such as school gym facilities; and engaging with a local farm for pupils to carry out work to raise self-esteem.

(Brown 2018:20)

It is a quantum leap to conclude that the provision detailed will improve matters; for example, that working with a local farm would promote self-esteem, that elusive and ephemeral understanding of self. This paper is in part being written close to the route travelled by the Tolpuddle Martyrs on their way to Australia. Perhaps their view of working on a farm might contradict Brown's conclusion.

The impact on mental health/well-being through the implementation of policy is displayed graphically as follows (Brown 2018: 46):

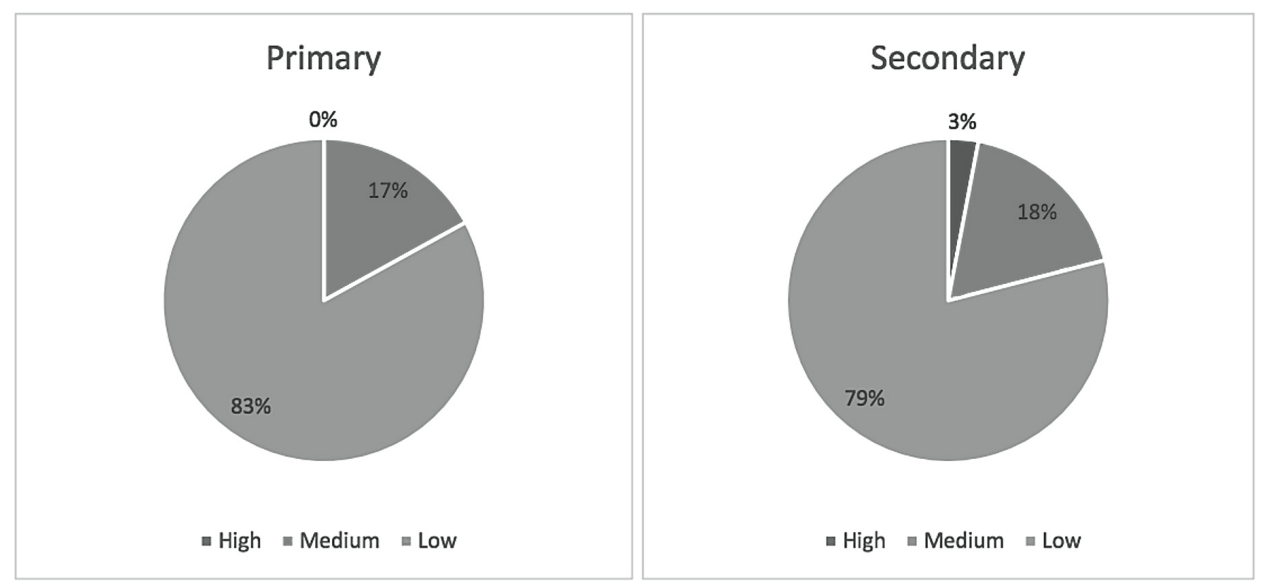

Figure 1: Pie Chart shows the overall extent to which equality policies promoted mental-health and wellbeing

It is not immediately clear what these charts actually depict. Perhaps Brown's own words are pertinent:

This review intended to understand how schools view their statutory duties in relation to mental health and wellbeing and developing respectful school communities. This was a desk-based study only, direct contact was not made with schools to verify whether activities cited within their policies were an accurate representation of what was being implemented, or to check whether they were carrying out activities to promote mental health and wellbeing that were not referred to within their policies.

(Brown 2018:20) 
It is important to note therefore, that this study does not provide a reliable evaluation of the activities that schools are doing to promote mental health and well-being. The limitations set out above should be carefully considered before accommodating the findings of this study.

\section{SELF-HELP - LITERATURE}

This is a multi-billion-pound industry. A visit to a bookshop will reveal how much this psychological cuckoo has extended its reach. Writers in the field such as Paul McKenna, Tony Robbins, Jon Kabat Zin and even crossover writers such as Ruby Wax have become influential and indeed rich. Robbins alone, is estimated to be a demibillionaire, in dollars at least.

Some like Wax, the chancellor of Southampton University, has an academic track record. Her story is a fascinating migration from being a TV script editor and comedian to being Visiting Professor in Mental Health Nursing at the University of Surrey in 2015. Most of those speaking and writing in this field have a more opaque academic background. A hallmark of many of the publications in this field is that they lack both an evidential basis and could in many cases be deemed to be idiosyncratic. Dolby, ${ }^{23}$ in her study of over 300 such books, suggested a definition of the genre as:

Books of popular non-fiction written with the aim of enlightening readers about some negative effects of our culture and worldview and suggesting new attitudes and practices that might lead them to more satisfying and more effective lives.

$(2005: 38)$

The accessibility of the style of these books could well amplify their influence. Anecdotally, many staff in the schools interviewed base much of their 'therapeutic interventions' on this type of literature. Significant numbers of these publications are true to their descriptor in that they are about 'self-help'. Their egocentric framework can easily lead to a reductionist view of mental health/well-being by ignoring the social context.

It is, perhaps, reasonable to ask whether the heavily marketed Mental Health First Aid (MHFA), ${ }^{24}$ which is widely used for Continuing Professional Development (CPD) in schools, could share a similar conceptual framework. Undoubtedly, it

${ }^{23}$ Dolby, S. K. (2005). Self-Help Books: Why Americans Keep Reading Them. Urbana: University of Illinois Press.

${ }^{24}$ Mental Health First Aid (2017) Mental Health First Aid England recognised in list of 


\section{THE BUCKINGHAM JOURNAL OF EDUCATION}

has increased a large number of peoples' confidence in dealing with colleagues and friends presenting mental health/well-being issues. However, this is from the conclusion of Bell et al. $(2018: 7)^{25}$

There is consistent evidence that MHFA training raises employees' awareness of mental ill-health conditions, including signs and symptoms. Those trained have a better understanding of where to find information and professional support and are more confident in helping individuals experiencing mental ill-health or a crisis.

However, the comment was also made that:

There is no evidence from the published evaluation studies that the introduction of MHFA training in workplaces has resulted in sustained actions by those receiving the training or that it has improved the management of mental health in the workplace.

(Bell et al. 2018:7)

A further critique was also offered by Defher (2016:2): ${ }^{26}$

MHFA ensures psychiatrization of distress through its practice of reductionism. Collapsing the social, political, cultural and economic complexity of human distress into one single aspect of the flawed mental interiority of the individual. MHFA exonerates contextual, socio-political factors whilst maximising attention to individual pathology.

\section{PREVALENCE STUDIES}

These state the extent of the problems around mental health/well-being, usually by defining the parameters of their analysis. These parameters could be apposite or

Europe's fastest growing companies. https://mhfaengland.org/mhfa-centre/news/201704-07-mental-health-first-aid-recognised-in-list-of-euro (Accessed 23/8/2019).

25 Bell, N., Evans. G., Beswick. A. and Moore, A. (2018) Summary of the evidence on the effectiveness of Mental Health First Aid (MHFA) traing $n$ the workplace., Buxton, Health and Safety Executive.

${ }^{26}$ Defehr, J. (2016) Inventing Mental Health First Aid: The Problem of Psychocentrism. Studies in Social Justice, Volume 10, Issue 1, 18-35, 2016. Ontario, University of Windsor. 


\section{PUTTING A STICKING PLASTER ON A GAPING WOUND}

open to question. It is important to ask what is included and what is excluded in terms of mental health/well-being in the study.

Mention has already been made of DSM-5. Lewisohn et al. (1993) ${ }^{27}$ used an earlier version, DSM-3 (1980), to evaluate the incidence of depression and other DSM-3 disorders in high-school students. They concluded that:

The Schedule for Affective Disorders and Schizophrenia for School-Age Children was used to collect diagnostic information; $9.6 \%$ met criteria for a current disorder, more than 33\% had experienced a disorder over their lifetimes, and $31.7 \%$ of the latter had experienced a 2 nd disorder. High relapse rates were found for all disorders, especially for unipolar depression (18.4\%) and substance use (15.0\%).

Leaving the statistical 'smokescreen' to one side, their analysis indicates a large number of students exhibiting some level of psychiatric morbidity. You would not want to see these figures in a teacher recruitment advertisement. However, Pickersgill (2013), ${ }^{28}$ critiquing the later version of DSM (DSM-5), identifies a trend:

In some senses, there is nothing especially novel about the debates noted above: critics have long attacked the validity and reliability of the DSM, and indeed the wider kinds of medicalisation it is often deemed to promote. Relating to this are criticisms of the role of drugs for mental health conditions. The pharmaceutical industry can be regarded as what Jutel calls an 'engine of diagnosis', which helps to power changes to the APA nosology and then becomes further embroiled in the processes of medicalisation that help to support 'pharmaceuticalisation'.

27 Lewisohn, P. M., Hope, H., Roberts, R. E., Seeley, J. R., and Andrews, J. A. (1993) Adolescent psychopathology: 1. Prevalence and incidence of depression and other DSM111-R disorders in high school students, Journal of Abnormal Psychology, 102 (1), $133-144$.

American Psychiatric Association (1980013) Diagnostic and Statistical Manual of Mental Disorders, 3rd Edition (DSM-3). Washington DC. American Psychiatric Association.

28 Pickersgill, M. (2013) Debating DSM-5, diagnosis and the sociology of critique. London, BMJ journals. 
In challenging the reliability and validity of the DSM franchise, he also challenges the very basis of the analysis of incidence.

In December 2016, Public Health England published Mental Health of Children and Young People in England. ${ }^{29}$ This is a mine of statistical information on the subject. The document will provide you with information about the incidence of anxiety, schizophrenia, eating disorders and many others. It is possible to critique the study around the diagnoses that underpin the study; and perhaps, too, to criticise the graphical presentation and its recourse to emojis and piggy banks. However, that is to detract from a significant attempt to identify the magnitude of the problem. Causation is noted within the text, and effective intervention strategies are identified. It is an alarming document that hints at a problem of epidemic proportions. A more serious critique is that it does not 'join up the dots' in an adequate manner. There is within its presentation a tendency to view mental health/well-being issues in 'silos' - e.g. there is the incidence of the depression silo and the eating disorder silo. Is this an appropriate approach or are these very real issues the evidence of a more holistic dysfunction, where the real need is societal re-engineering rather than symptomatic response?

\section{CONCLUSIONS FROM THE LITERATURE REVIEW}

The following are advanced as emergent conclusions from the exploration of the literature around mental health/well-being.

There is a lack of definition about what good or indeed deficient states of mental health/well-being exhibit. In turn, this impairs the substance and quality of significant published research. And in turn, it is suggested that this leads to confused conceptual frameworks being advanced, e.g. the research which utilises DSM-5 (2013) or Brown's diversion from the review from policy into personal assertions. Confused conceptual frameworks, allied to concerns about research, provide an unstable substrate on which to develop consistent and effective schoolbased programmes.

In much of the literature there is considerable focus on deficit, which tends to lead to responses in dealing with the pathology of individuals. Consequently, there is a reduction in focus on the creation of healthy environments. This certainly deflects strategic planning from creating healthy organisations and stands in marked contrast to research such as that undertaken by Riley, K. Coates, M. and

${ }^{29}$ Public Health England (2018) 'Mental Health of Children and Young People in England'. London, NHS. Digital. 


\section{PUTTING A STICKING PLASTER ON A GAPING WOUND}

Perez Martinez, S. (2018) $)^{30}$, Bingham and Bubb (2017) ${ }^{31}$ and Bingham (2013), ${ }^{32}$ which identify factors in school environments which are fertile for an holistic approach to mental health/well-being.

There is some evidence of the commercialisation of the provision of support for mental health/well-being. For example, whilst MHFA is a community interest company, it does exercise a dominance in provision. In 2017, the organisation, commenting on its listing by the Financial Times in the 1,000 fastest-growing European companies, stated that:

MHFA England provides courses teaching people to identify, understand and help a person who may be developing a mental health issue. The Community Interest Company's annual revenue has grown by $195 \%$ over the last three years, meaning the not-for-profit business is placed at number 547 on the list as compiled by data provider Statista. Entry into the list is only available for companies with revenue of at least $€ 1.5 m$ generated in 2015 , which are headquartered in one of 31 European countries.

The movement towards increased lay response, allied to the reduction in availability of professional services like CAHMS, could de-professionalise the provision for individuals displaying diagnosed or emergent pathology.

The picture emerged of a complex situation with an unclear interface between schools and the wider society. It is suggested that there is no more tragic focus on adolescent health and well-being than suicide. It may well be that the conclusions reached in the annual survey around this area undertaken by a team from the University of Manchester (2017) ${ }^{33}$ are both poignant and pertinent:

Many of the stresses that contribute to suicide risk are common in young people, most of whom overcome them without too much difficulty. For a minority, however, the stresses are serious and the risks are real. For this

\footnotetext{
30 Riley, K. Coates, M. and Perez Martinez, S. (2018) Place and Belonging in Schools; unlocking possibilities. London, Institute of Education.

31 Bingham, D., and Bubb, S. (2017). 'Leadership for Wellbeing' in Earley, P. and Greany, T. (Eds.) School Leadership and Education System Reform. London: Bloomsbury.

32 Bingham, D. (2013). 'Wellbeing in educational settings' in M Dawe (Ed.), The School Leader's Toolkit: Practical Strategies for Leading and Managing. London: Sage.

${ }_{33}$ Suicide by children and young people (2017). National Confidential Inquiry into Suicide and Homicide by People with Mental Illness (NCISH). Manchester: University of Manchester, 2017.
} 
reason, distress in young people should not be dismissed as transient or trivial.

The circumstances that lead to suicide in young people often appear to follow a pattern of cumulative risk, with traumatic experiences in early life, a build-up of adversity and high-risk behaviours in adolescence and early adulthood, and a 'final straw'). This event may not seem severe to others, making it hard for professionals and families to recognise suicide risk unless the combination of past and present problems is taken into account.

(University of Manchester 2017:21)

\section{RESEARCH METHODOLOGY}

The literature review points to schools facing a complex web of problems. The research, though limited in scale, seeks to explore how some schools corresponding to both the individual needs of students and the perception of a rising incidence mental health/well-being problems whilst undertaking the 'day job' are providing formal education. The latter often delivered in the context of having high levels of accountability within the institution. The authors have sought in a non-pejorative manner to explore the provision being made in English secondary schools to support mental health and well-being.

This research study utilises a case-study approach (Yin 2014) ${ }^{34}$ with senior staff in English state and independent secondary schools to uncover perceptions and illuminate the extent and forms of mental health and well-being provision viewed in English independent and state-sector secondary schools. It is argued that a mixed methods approach used in this small-scale study is best suited to educational research (Briggs et al. 2012) ) $^{35}$ to uncover key facets of the extent of this provision. As a piece of interpretative research, the study was not testing a hypothesis but sought to understand the current provision of mental health/ well-being provision for young people in state and independent secondary schools.

The methodological approach taken was through an online survey and semistructured interviews. Data collection was made by an electronic survey to an invited sample group of participants for an initial understanding. Survey questions

\footnotetext{
34 Yin, R. K. (2014). Case Study Research: Design and Methods (Applied Social Research Methods) ( $7^{\text {th }}$ edn.). Thousand Oaks: Sage.

35 Briggs, R. J. A., Coleman, M., Morrison, M. (2012). Research Methods in Leadership and Management ( $3^{\text {rd }}$ edn.). London: Sage.
} 
used a six-point Likert scale, rank-order and multiple-choice questions for perception gathering.

A further purpose was to identify participants and collect data for the interview research questions. Following on from the completion of the survey we invited 15 leaders, who had opted in to respond to the survey to participate in interviews for deepening the understanding of the research questions. Semi-structured or structured interviews offer a 'flexible strategy for discovering'; their purpose guiding the conversation to elicit rich and detailed content for qualitative analysis (Lofland et al. 2005). ${ }^{36}$

\section{SAMPLE CONSIDERATIONS}

The selection of the schools for the survey questionnaire was conducted by way of contacts derived predominantly from a LinkedIn interest group who self-selected to become part of that group of school leaders. Participants were not from one geographical area, neither from one particular school phase as we were looking for a snapshot around provision of mental health strategic support and implementation. Selection was made based on participant's role as self-selecting as senior staff at the level of headteacher/principals or deputy headteachers/vice principals in their LinkedIn profile and therefore they would be involved in strategic decision-making. This eliminated any potential concern over possible influence or coercion of subordinate or junior staff. The approach to the school/academy was made through the headteacher/principal through direct approaches through convenience sampling via the Linked in special interest group.

However, as the desired level of participation was not arrived at, further participants were invited through a 'snowballing approach' or through purposive sampling. An invitation to take part in interviews with members of the senior leadership teams of schools/academies was by way of 'convenience sampling' (Robson 2011) ${ }^{37}$.

The sample size arrived at was 24 completed online surveys and 9 senior staff interviews (senior staff at the level of headteacher/principals or deputy headteachers/vice principals) the majority of whom play a strategic role in student pastoral care.

${ }^{36}$ Lofland, J., Snow, D. A., Anderson, L. and Lofland, L. (2005). Analyzing Social Settings. ( $4^{\text {th }}$ edn.). London: Belmont CA: Wadsworth Publishing/Thomson Learning.

${ }^{37}$ Robson, C. (2011). Real World Research (3 ${ }^{\text {rd }}$ edn.). Chichester: Wiley. 


\section{ETHICAL CONCERNS}

Conventional ethics approval through University College London (Institute of Education) provision including data registration as indicated above. The data from questionnaires and semi-structured interviews with senior school-based staff has been anonymised. It was made clear to the senior staff at the level of headteacher/ principals or deputy headteachers/vice principals that the interviews would remain confidential unless safeguarding or issues of criminality emerged during the interview. The basis of the interview was in terms of 'opt in'. The issues of confidentiality and the option to withdraw from the interview was discussed. It was made clear how the data would be used in the final outputs from the project.

As sampling of the questionnaires and the interviews were predominantly made through LinkedIn, there is by implication a strong element of 'opt in', which may skew the results. For instance, it may be that respondents might have wished to be involved in the research project to merely 'showcase' their initiatives in the area of mental health/well-being rather than contributing to an authentic understanding of the provision.

Analysis of the survey data was conducted thematically. Data analysis for the interviews was conducted manually, through transcription of all the recorded interviews using a coding method to arrive at the key themes of the research. A thorough saturation of codes has provided rich thick descriptions (Miles and Hubermann 1994) ${ }^{38}$ in the data. The two data sources - survey and interviews were analysed through thematic analysis, constant comparative method (Glaser and Strauss 1968) ${ }^{39}$ and comparison made between the two data sources.

Findings were presented from interpretive and inferential analysis, as a mixedmethods approach was used. Braun and Clarke's (2006) ${ }^{40}$ five-step framework was used in reflecting on the different stages of analysis to arrive at the key themes at play in this evaluation which are portrayed in the Conclusion.

\section{DATA AND ANALYSIS}

Twenty-four people completed an online survey, and it was noticeable that almost every question was completed by all 24 participants.

\footnotetext{
38 Miles, M. B., and Hubermann, A. M. (1994). Qualitative Data Analysis: An Expanded Sourcebook. ( $2^{\text {nd }}$ edn.). Thousand Oaks, CA: Sage.

${ }^{39}$ Glaser, B. G., and Strauss, A. L. (1967). The Discovery of Grounded Theory: Strategies for Qualitative Research. New York: Aldine.

40 Braun, V. and Clarke, V. (2006). 'Using Thematic analysis in Psychology'. Qualitative Research in Psychology, 3(2), 77-101.
} 
Two thirds of those surveyed said that there was a clearly organised pupil support system having well-being and mental health mandated as part of the role ( $71 \%$ of those surveyed said yes, with $30 \%$ saying no). This means that a third didn't have such a system and there were comments about resourcing and early stages of development.

In terms of a framework for student support to identify concerns over wellbeing, diagnosis, support, referral and the dissemination of information back into the school/academy from external agencies, $75 \%$ (18) said there was, but 25\% (6), almost a third, said that there was not. A comment from one school showed that there were regular weekly meetings led by the deputy head having a pastoral lead with clearly identified channels for resource allocation and referral to external agencies. However, in other comments it was not quite clear how these frameworks were then enacted upon.

Schools surveyed identified regularly updated protocols related to well-being and referral. The most often see was anti-bullying (92\%), being 22 out of 24 schools, with referral at $71 \%$. For both gender issues and disability, 13 schools said that they did (54\% apiece); for faith issues it was 11 schools out of 24; similarly for concerns around ethnicity at 11 schools. For promoting self-esteem, 50\% (12) of schools indicated having a protocol. One school had protocols on counterterrorism, while another had protocols on LGBT. Only one school did not have any protocols.

In terms of fora for students to discuss mental health and well-being issues and concerns, $75 \%$ of schools self-identified as giving students opportunities (18), with two schools indicating that they had other ways in using external organisations, as part of PHSE and assemblies, and one school was part of a university research programme. However, 4 schools said that they did not offer anything.

All but one of the 24 schools indicated that there was a nominated person/s with a brief to monitor the well-being of individual pupils. 16 out of 24 schools indicated that they were appropriately trained, but a less positive third (8) indicated that they were not. Furthermore, over $60 \%$ (14) of schools identified that there was a trained student counsellor in place. However, 30\% (7) said not, but additional comments indicated different provision, in that external professional counsellors were used and/or the student welfare officer was involved, as well as working with external psychologists/ psychiatrists and the school's education psychologist.

In terms of reports to governors, trustees or directors being a standing item on the agenda, overall, this was not the case, with two thirds (16 schools) saying that it was not, and a third (8 schools) saying that it was. Overwhelmingly, schools did not have an audit of specialist support as a standing item on the agenda, with 19 schools saying no, but 4 confirming that there was.

However, in contrast 21 out of 24 schools said that they did have a formal conduit whereby discussions around student well-being and mental health were 
taken to senior leadership. Two further schools expanded on this, with one stating: 'Once a week the pastoral team with the DSL have a "core group" meeting.' Where the answer was classed as 'other', it was accompanied by the comment: 'until student well-being is clearly defined - not sure it can be', raising the complex issue of defining well-being - a term that is ambiguous.

Over the question as to whether trained buddy system or peer mentors was in operation the responses were almost exactly $54 \%$ said yes and $45 \%$ said no between schools that did and those that did not.

Whether schools had adopted a defined model of well-being was also approximately divided into equal responses, with 10 stating that they didn't and 12 stating that they did. Two did not respond, one stating: 'Not sure of the question ("Accepted understanding" - definition of? If so, we are working on this, to differentiate normal ups and downs from patterns)', while another said that 'while teachers seems to be clear about it students are not'.

One question asked about the existence of explicit values, mission and vision statements. Twenty-one schools either agreed strongly or agreed that they existed in their context. A mere two had no real clarity as to whether there was or not. The final school (of 24 respondents) indicated that the mission statement 'is currently being redeveloped'.

In terms of the curriculum having age-related content focused on a number of areas, there was unanimous agreement from the 24 schools that they did for antibullying, with anti-racism, gender and the availability of mental health information also returning very high scores, although mental health information for staff to share with students was at a lower scoring, with $37.5 \%$ (9 schools) making it available.

Also scoring highly (17 schools) was curriculum time built in for challenging discriminatory ideologies and study skills. Stress-reduction techniques such as mindfulness were part of the curriculum for 15 out of 24 schools $(62.5 \%)$ timetabling this element. Three schools made time for studying how to use our brains. A further question focused on whether if there was a supportive curriculum, whether it was delivered by a specialist in mental health and well-being - where 20 schools said that it was not and only 3 said that it was. A further school commented that they did not understand the comment 'a supportive curriculum'.

Whether the school monitored student workload was responded to by all and was approximately equally split between those that did (13) and those that did not (10), with a further school indicating that it was 'only in Year 11 and not consistently'.

Whether there was CPD for the provision of mental health and well-being was also almost equally spread between those that did and those that didn't (54\% did while $42 \%$ did not with 13 and 10 schools respectively). The final school commented that there was 'some but limited'. 
A high 70\% (17) indicated that staff had not undertaken mental health training courses to equip them to respond to well-being and mental health issues, while 3 $(12.5 \%)$ indicated yes. Interestingly, the final four surveyed indicated that there is movement and that other solutions might be offered, with comments such as: "this is currently ongoing', 'Mental health first-aid training has started to be rolled out', 'head of year has done some training and we have had several external speakers to talk to staff', 'mental health first-aid courses are very expensive' and 'some are especially trained but all staff are aware of basic mental health and well-being issues via safeguarding training and periodical mental health input'.

Overwhelmingly, school mental health and well-being was not part of staff induction (80\%), with a mere 3 schools (12.5\%) having it established. The two remaining schools commented that 'it can be covered under safeguarding but not its own area', and that 'there is a lot of discussion on workload and we work in a very supportive environment. However, I would not say that mental health/wellbeing is an explicit part of the induction process.'

In terms of staff communication over updates to curriculum changes around mental health policies for emergent issues, such as addictive behaviours of social media or patterns of substance abuse, the responses indicated that $42 \%$ of schools (10) did receive updates, while a rather more $58 \%$ (14) were not kept abreast.

Almost 61\% (14) of participants agreed that there was not ongoing training for any counsellor in place, particularly around supervision, while $26 \%$ (6) confirmed that there was. Three responses commented that external provision of trained counsellors was used, that 'only because it is so new' and one further participant indicated that they did not think it was relevant.

On whether stress reduction techniques were advocated and taught to all staff, $30 \%$ (7) said that they were, while a larger 54\% (13) indicted that they were not. Four schools commented that: 'these are taught, but the causes of stress are still there: constant changes in the timetable, constant last minute covers, lack of communication by some senior staff creating last minute workload'; 'Yes, but not very well! Well-being is promoted through a 10-minute lunchtime walk'; 'Yes, this is an explicit focus of the staff day in February'; 'Mindfulness sessions are available for those staff who are interested'.

The final question referred to typical stress-reduction techniques seen in schools taken from those listed in the survey, being: spaces for students to discuss wellbeing (7); mindfulness/cognitive based therapy (6); nutrition and mental health (3); student inclusion in wellbeing strategy creation (2); yoga (1); daily physical outdoor activity (1); and one school indicated that 'not as whole-school, all-pupil approaches. Several are used informally.' Two participants made no response.

Nine semi-structured interviews were also carried out. In nearly all of the cases the initial approach was to the head teacher/principal. In eight of the nine 
Table 1: Summary of schools used in the semi-structured interviews.

\begin{tabular}{|l|l|l|l|}
\hline School & Category & Mixed/Boys/Girls & Setting \\
\hline A & V1th Form & Mixed & Urban \\
\hline B & Comprehensive & Mixed & Suburban \\
\hline C & Comprehensive & Mixed & Suburban \\
\hline D & Grammar & Mixed & Urban \\
\hline E & Grammar & Mixed & Suburban \\
\hline F & Independent & Boys & Suburban \\
\hline G & Comprehensive & Boys & Urban \\
\hline H & Independent SEN & Mixed & Urban \\
\hline I & Comprehensive & Mixed & Urban \\
\hline
\end{tabular}

interviews we were referred to a designated member of staff who had responsibility for this area, or as one head teacher put it, 'deals with that kind of thing'. Approximately half of the interviews were recorded with the agreement of the interviewee. The nature of the schools together with an anonymised designation are given in the following Table 1.

The interviews were subsequently analysed using the constant comparative method, and a series of themes were identified; these form the basis for the following discussion and are further distilled in the conclusion.

\section{CHANGES IN SOCIETY}

All of those interviewed spoke in general terms about changes within society. These are identified as: violent behaviours, cyber-bullying, personal and gender identity. There is a perception that problems are worsening and that new contributory factors such as social media and increasing challenges around gender identity are exacerbating the situation. There is widespread concern around the above issues within society as a whole and also within schools. The University of Manchester, in its Suicide by Children and Young People. National Confidential Inquiry into Suicide and Homicide by People with Mental Illness (NCISH) (2017), ${ }^{41}$ suggests that this is an extremely complex area, and where significant problems are exhibited by students they are usually multifactorial.

41 National Confidential Inquiry into Suicide and Homicide by People with Mental Illness (NCISH) (2017) Suicide by children and young people (2017). Manchester: University of Manchester. 
All those who were interviewed were trying to manage difficulties with pupils whilst at the same time finding that support from external agencies such as the Child and Adult Mental Health Services (CAMHS) and the availability of educational psychologists was difficult to access. This was frequently put down to budgetary cuts at a regional and national level.

Four interviewees identified specific areas which were requiring a particular response: looked-after children, knife crime, bereavement and children on the autistic disorder spectrum. Three of these are commented on in further detail later in the text.

The interviewee from school D specifically raised the issue of bereavement. Obviously, within a school population this will surface. They noted:

That there was a big impact of the death of grandparents. She advanced the argument that they were occupying an increasingly important role in the lives of the students.

Overall, family dysfunctionality was barely commented on. The fact that significant numbers of children experienced familial transition as families fractured and regrouped was perceived as almost being 'background noise'.

In many ways, examination stress was considered a similar phenomenon. Three schools were advocating resilience training. However, the programmes employed seem to lack evidential basis. There was little consideration given to changing the ways in which schools are structured and run.

\section{FRAGMENTATION}

Seven of the nine staff interviewed revealed a level of fragmentation in the response that was being made to the needs presented by children. Whilst in many cases there was evidence of a 'pastoral system', a model perpetuated from the 1970s and 1980s, the emphasis of the role had changed towards monitoring and securing academic performance.

The year heads were mainly performing an academic role, with the student managers, one of them was a life coach, providing a lot of the hands-on pastoral care.

(School D).

We have a fairly conventional teacher-led year system but this is having increasing importance in terms of enhancing student performance and their name is being changed to 'Directors of Learning'. 
In another, the sixth-form college, there were three vice principals who handled significant pupil issues but who did not engage with the designated well-being team.

The most extreme level of fragmentation was found in the school where there was no identifiable referral process. It is our view that this is extremely unusual in UK schools.

The pattern emerged of a series of largely disconnected approaches to the issues around mental health and well-being. Even in School E, where there was a well-developed programme which sought to address mental health/well-being issues, this level of disconnect was still evidenced.

There were also a number of 'para-educationalists.' In School C a new initiative had been developed:

We have a Student Engagement Team; this consists of four full-time and one part-time members of staff and includes an ex-policeman, someone who has a background in working in a PRU and a part-time chaplain. They do some group work and individual work. The chaplain has a youth-worker background and was responsible for services et cetera.

A number of schools have a counsellor; one even had two. Discussions suggested that these have some foundational training at least. The essential problem seems to be that these counsellors' requirement to work with a high level of confidentiality meant that those interviewed had very little information as to what they actually did or which pupils were involved with them. In several of the schools, even the referral process was obscure. School D, an independent school, employs a counsellor for three days a week. The parents were charged for the counselling though costs could be waived if this was thought appropriate. Again, confidentiality prevented any assessment or accountability of the counsellor's role, especially as this could involve self-referral by the pupils themselves. In three of the schools, reference was made to the fact that the counsellor received supervision. This is in line with their accepted professional practice. However, the supervisor was not school-based, and a question mark must hang over the accountability being exercised by the schools.

Over half of the schools had taken advantage of external organisations. Some had been utilised for professional development, but a number were delivering directly to pupils. These included MIND, the Samaritans, and some local initiatives like Modelling Active Relationship Skills for young people (MARS) were also involved. One school (School B) also had a subscription to Kooth. This is an online provider of counselling which allows self-referral and is available from midday to 10 p.m. weekdays, with some weekend availability. The interviewee suggested that there were quite a few schools who paid subscriptions for this service for their pupils. There was nothing to suggest that this was either positive or negative. It is 


\section{PUTTING A STICKING PLASTER ON A GAPING WOUND}

suggested that it is a significant step for the school to fund access to a service over which they have no exercise of accountability.

\section{REACTIVE PROVISION}

While several schools sought to provide input for all pupils either through specialist sessions or through a development of Personal Health and Social Education (PHSE), the majority of responses focused on individuals who were presenting problems. The interviewee from School A commented:

Well-being/mental health was not in the curriculum, the latter contains some life skills but these were mainly centred on UCAS.

There was evidence in the interviews of a caring and compassionate response; however, the focus remained on the presenting problem. The discussions remain rooted in: how can support be given to a child being impacted by cyber-bullying or one becoming involved with substance abuse?

Two schools identified anxiety amongst pupils identified as being on the Autistic Disorder Spectrum as a significant part of their workload. Their perception was that in the face of budgetary cuts, Special Education Needs provision had been reduced. A number of vulnerable pupils had felt unsupported and had turned to those with a mandate for mental health/well-being. The interviewee from school A noted:

There is an added problem which is beginning to overwhelm our provision. As the College reduced its SEN provision they have a significant number of students on the Autistic Disorder Spectrum. With this reduced support many of these students were becoming very anxious and the well-being team are finding that more and more of their time is spent supporting them.

Many of those interviewed spoke about examination stress. It was perceived across those interviewed as a big concern, but essentially there was no strategic response to address it. It was understood as an accepted phenomenon. Mitigating tools were put in place to respond to this external pressure on students, such as mindfulness and resilience training. Even in compassionate schools, the phenomenon was set against public perception of the need to achieve strong exam results and attain high performance. The changes in the exam grading system were also held to have made it more difficult for students and in turn raise stress levels.

There is a focus on symptoms rather than reaching behind these to establish more generic provision. There are exceptions, but our research showed that these were in a small minority. A strong picture emerges that the response to well-being/ 
mental health problems within the schools varies and at times was somewhat 'niche', and that very little attention is given to structuring the schools to support the many. One interviewee spoke of: 'the school as an examination factory with compassion as a luxury' (School B).

\section{PROFESSIONAL DEVELOPMENT}

Designated staff with responsibilities in this area often lack meaningful professional development and often become involved because of an interest in the area. It is not uncommon to find non-teaching staff, e.g. teaching assistants (TAs), and even a librarian taking a lead role in one school.

There is some evidence of whole-school training, e.g. Mental Health First Aid (a New Zealand-based course). Frequently there is limited professional development in this area. A surprising result was that there was no evidence of induction in this area given to staff entering schools.

\section{LIMITATIONS}

The appeal in participants completing the survey questionnaire and interviews with members of the senior leadership teams of schools/academies is 'convenience sampling'. The constraints of this small scale and unfunded research mean that the preferred option of truly random selection is not feasible. However, care has been taken within the context of this research to engage only with schools who have not (to our knowledge at least) showcased specific initiatives in the area of well-being/ mental health. The aim was to explore provision that is being made on a more general basis rather than selecting examples of alleged good practice, concurring with Yin's argument for case studies striving for analytic generalisations (2014) and where Flyvbjerg's point of departure is of a researcher looking at common views of a target group which is applicable for this study (Flyvbjerg 2006). ${ }^{42}$

The limitations of the study are recognised by the authors. In particular, they are aware of the small-scale nature of the research, and also of the fact that with limited resources they have had to undertake a degree of convenience sampling. Even so, the conclusions reached have a degree of validity derived from the consistency of responses from both the questionnaires and the semi-structured interviews. It is hoped that what is in effect a 'ranging shot' could lead to a more extensive and comprehensive study.

${ }^{42}$ Flyvbjerg, B. (2006). 'Five misunderstandings about case-study research'. Qualitative Enquiry, 12(2), 219-245. 


\section{PUTTING A STICKING PLASTER ON A GAPING WOUND}

\section{CONCLUSION}

There was unanimity amongst those who were interviewed that the problems of society are getting worse. These societal problems are understood as being readily imported into schools, e.g. violence, cyber-bullying and issues around personal acceptability and identity.

Concurrently, there is a perception that specialist support services such as CAHMS were less accessible. The staff in schools argued that the reduction in such support was as a result of budgetary cuts that had been made within the services. The view was expressed that such budgetary attrition was impacting the provision of support within the schools as well. Three of those interviewed were concerned that their own role was under threat from financial constraints in their schools. The situation was exacerbated by reductions in the levels of support given to students with learning difficulties, which in turn had created an internal pool of stress. One respondent commented that their 'welling provision' was in effect taking over the support of students on the Autistic Disorder Spectrum, as existing support had been cut.

Overall, a picture emerged of a response to mental health/well-being that is fragmented, inconsistent and rooted in being reactive to presenting problems rather than securing this for the many. The authors found that the provision was multi-layered with the 'dots not being joined up'. Schools have had pastoral systems since the 1970s/1980s. These staff were usually highly paid middle leaders. Over the last 15 years this role has often passed to teaching assistants. Such pastoral systems are still the main agency for external referral, however, in the majority of cases those engaged in well-being/mental health are not integrated with this seminal pastoral frontline. In five schools, where semi-structured interviews were carried out, there were trained counsellors. The cloak of confidentiality meant that patterns of referral and response are unclear. The latter situation can be exacerbated where pupil self-referral is an accepted option.

It was routinely noted that there was considerable anxiety amongst pupils about their performance in testing and in summative examinations. Is it disingenuous to suggest that the origins of such pressure lie more with the accountability of schools and staff than with a desire for students to achieve? Whatever the cause, it is a significant dimension in terms of mental health/wellbeing. There appeared to be an acceptance that coercive pressures within the system to enhance examination success were inevitable. Palliatives such as mindfulness, yoga and resilience training were being offered, but there was no discussion of a fundamental re-engineering of the assessment process to remedy the situation. 
The study suggests that there is an absence of coherent thinking around mental health/well-being. In turn, this impacts the professional development being undertaken within schools. Many of those supporting well-being/mental health are committed professional staff within the schools but they often draw on a 'well of common sense' rather than structured and evidence-informed training. This knowledge vacuum is being filled, in part, by commercial concerns such as MHFA or inputs from charities such as MIND or Place2Be. It was also noted that mental health/well-being did not feature in the induction of newly appointed staff.

In the literature review there was some discussion of the Green Paper (2018). This recognises the existence of problem around mental health/well-being in schools and also makes a commitment to provides resources to mitigate its impact. It places particular emphasis on the provision of trained personnel in schools and the availability of improved access to mental health services. It is suggested that there is a need to understand mental health/well-being as an entitlement for the many and not just about resolving minority manifestations of pathology. The current situation is unlikely to be solved by flooding schools with the wellintentioned but rather by recruiting and training skilled practitioners. An effective response may well mirror the adage that 'less is more'. 